\title{
Rationale for Hypertonic Saline Therapy for Cystic Fibrosis Lung Disease
}

\author{
Robert Tarran, Ph.D., ${ }^{1}$ Scott Donaldson, M.D., ${ }^{1}$ and Richard C. Boucher, M.D. ${ }^{1}$
}

Cystic fibrosis (CF) is caused by alterations in the CF transmembrane conductance regulator $(C F T C R)$ gene. More than 1400 mutations in the $C F T C R$ gene have been described, but the most common mutation (noted in $70 \%$ of $\mathrm{CF}$ chromosomes) is $\Delta \mathrm{F} 508$. Alterations in the CFTCR gene result in deranged sodium and chloride ion transport channels. This leads to failure of airway epithelia to hydrate their surfaces normally, particularly in response to infectious or toxic insults. Additional effects include mucus adhesion to airway surface, chronic inflammation, and infections. The concept that airway surface dehydration can cause CF-like lung disease is supported by in vitro data and in vivo animal models. Rehydrating airway surfaces may reduce or prevent lung injury and damage. Short- and longer term studies have shown that inhalation of hypertonic saline is well tolerated and improves lung function, reduces exacerbations, and improves quality of life in $\mathrm{CF}$ patients. This review discusses the importance of airway epithelial sodium and chloride channels in the pathogenesis of $\mathrm{CF}$, and strategies (particularly the use of inhaled hypertonic saline) to reverse or minimize lung inflammation and injury in this disease.

KEYWORDS: Cystic fibrosis, cystic fibrosis transmembrane conductance regulator (CFTCR) gene, hypertonic saline, sodium and calcium channel, osmotic gradient

The syndrome of cystic fibrosis $(\mathrm{CF})$ reflects a spectrum of more than 1400 mutations in the $\mathrm{CF}$ transmembrane conductance regulator $(C F T C R)$ gene. ${ }^{1}$ The CFTCR gene is large, $\sim 250 \mathrm{~kb}$, and resides on chromosome 7.,3 The CFTCR protein encoded by the CFTCR gene is a 1480 amino acid protein that typically resides in the plasma membrane of epithelial cells. ${ }^{4}$ This protein appears to have many functions, but a unifying theme is that it acts at virtually all sites as a protein kinase $\mathrm{C}$ and cyclic adenosine monophosphate (cAMP)regulated chloride $\left(\mathrm{Cl}^{-}\right)$channel. ${ }^{5,6}$ Interestingly, in the sweat duct, CFTCR acts as a $\mathrm{Cl}^{-}$absorptive channel; in the pancreas, it serves to secrete $\mathrm{Cl}^{-}$, which is exchanged for bicarbonate $\left(\mathrm{HCO}_{3}-\right)$; and in the lung, it is involved in secretion of $\mathrm{Cl}^{-}$. Importantly, in the lung, the CFTCR protein has a second function acting as a regulator of the epithelial sodium $\left(\mathrm{Na}^{+}\right)$channel $(\mathrm{ENaC})$ and hence $\mathrm{Na}^{+}$absorption. ${ }^{7,8}$

There are five classes of mutations in the CFTCR gene that produce disease. The most common mutation, which occurs on $70 \%$ of all CF chromosomes, is a threebase-pair deletion that leads to a deletion of phenylalanine at position 508 of the CFTCR protein and is designated as $\triangle \mathrm{F} 508$. The molecular pathogenesis of this class of CFTCR mutations is relatively well understood. Typically, the absence of a phenylalanine at position 508
${ }^{1}$ Cystic Fibrosis/Pulmonary Research and Treatment Center, The University of North Carolina at Chapel Hill, Chapel Hill, North Carolina.

Address for correspondence and reprint requests: Richard C. Boucher, M.D., Cystic Fibrosis/Pulmonary Research and Treatment Center, CB\#7248 7011 Thurston-Bowles Bldg., The University of North Carolina at Chapel Hill, Chapel Hill, NC 27599-7248 (e-mail: rboucher@med.unc.edu).

Pediatric Pulmonology; Guest Editors, Bruce K. Rubin, M.D., Andrew Bush, M.D.

Semin Respir Crit Care Med 2007;28:295-302. Copyright (C) 2007 by Thieme Medical Publishers, Inc., 333 Seventh Avenue, New York, NY 10001, USA. Tel: +1(212) 584-4662.

DOI 10.1055/s-2007-981650. ISSN 1069-3424. 
leads to problems in intracellular protein folding and maturation that are part of the normal biosynthetic pathway of membrane proteins. ${ }^{9,10}$ Consequently, the $\Delta$ F508 CFTCR protein is "edited" out of the cell by molecular chaperones and a variety of intracellular degradative pathways. Hence, the molecular pathogenesis of this most common form of CFTCR mutation reflects the absence of a functioning CFTCR polypeptide in the plasma membrane. Other mutations can produce a nonfunctioning CFTCR $\mathrm{Cl}^{-}$channel at the apical membrane and/or a mutant CFTCR with abnormal ion permeation characteristics.

\section{CYSTIC FIBROSIS LUNG DISEASE}

CF lung disease fundamentally reflects a failure in the capacity of airway epithelia to normally hydrate their surfaces, particularly in response to infectious or toxic insults. Poor hydration of airway surfaces leads to reduced mucociliary clearance, adhesion of mucus to airway surfaces, and, ultimately, chronic bacterial infection of airway surfaces (Fig. 1).

Data from an in vitro well-differentiated cell culture model interfaced to a confocal microscope to measure airway surface liquid (ASL) volume were key in elucidating the importance of airway surface hydration in lung defense. ${ }^{11,12}$ The hydration of the normal airway surface (i.e., the volume of ASL), is determined in a highly water-permeable epithelium such as airway epithelia by ion transport processes that control the mass of salt $(\mathrm{NaCl})$ on airway surfaces. ${ }^{13}$ Normal airway epithelia have the capacity to remove (absorb) $\mathrm{NaCl}$ from or add (secrete) $\mathrm{NaCl}$ to airway surfaces (Fig. 2A). The absorptive pathway reflects the capacity to actively absorb $\mathrm{Na}^{+}$ ions, with $\mathrm{Na}^{+}$entering the cell from ASL through the

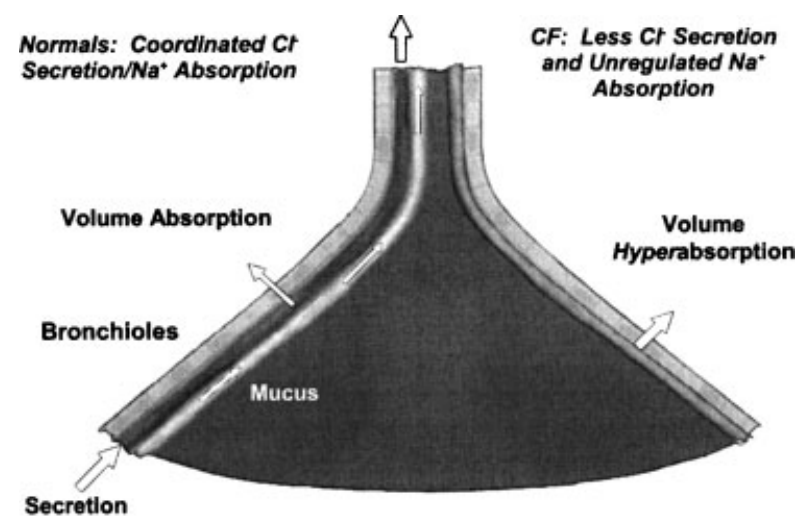

Figure 1 Schema depicting relationship of $\mathrm{Na}^{+}$and $\mathrm{Cl}^{-}$transport to mucus clearance and lung defense. (L) In health, $\mathrm{Na}^{+}$ absorption and $\mathrm{Cl}^{-}$secretion are coordinated to optimize airway surface hydration and promote the clearance of mucus from airway surfaces. (R) In cystic fibrosis, unregulated $\mathrm{Na}^{+}$absorption and diminished $\mathrm{Cl}^{-}$secretion produce a propensity for airway surface dehydration, mucus adhesion to airway surfaces, and, ultimately, chronic inflammation and infection.
ENaC. $\mathrm{Na}^{+}$ions exit the cell via the activity of a basolateral $\mathrm{Na}^{+}-\mathrm{K}^{+}$-adenosine triphosphate (ATP)ase. Chloride may be secreted from the cell by an apical membrane $\mathrm{CFTCR} \mathrm{Cl}^{-}$channel or a $\mathrm{Ca}^{2+}$-activated $\mathrm{Cl}^{-}$channel $(\mathrm{CaCC})$, with $\mathrm{Cl}^{-}$entering the cell principally via an $\mathrm{Na}^{+}-\mathrm{K}^{+}-2 \mathrm{Cl}-$ cotransporter. Regulation of the balance between absorption and secretion determines the net transport of ions across the epithelium and, hence, the mass of salt on an epithelial surface.

The processes that regulate the balance between $\mathrm{Na}^{+}$absorption and $\mathrm{Cl}^{-}$secretion are beginning to be elucidated (Fig. 2A). Important signals that are contained within the ASL itself include the triphosphate adenine nucleotide, ATP, and the adenine nucleoside, adenosine (ADO) ${ }^{14}$ ATP, interacting with luminal $\mathrm{P}_{2} \mathrm{Y}_{2}$ receptors, can slow the rate of $\mathrm{Na}^{+}$absorption and initiate/accelerate $\mathrm{Cl}^{-}$secretion via $\mathrm{PKC}$-mediated actions on CFTCR and $\mathrm{Ca}^{2+}$-mediated actions on CaCC. ${ }^{15}$ Adenosine can initiate $\mathrm{Cl}^{-}$secretion via cAMP-dependent activation of CFTCR and CFTCRdependent inhibition of $\mathrm{ENaC}$. Recent data have suggested that both systems are operative and important in regulating the balance of $\mathrm{Na}^{+}$absorption versus $\mathrm{Cl}^{-}$ secretion in normal airway epithelia. ${ }^{16}$ The quantities of ATP, and its metabolic product ADO, on airway surfaces are determined by the mechanical stresses imparted to airway epithelia during breathing that regulate the rate of ATP release from epithelial cells into ASL. ${ }^{17} \mathrm{~A}$ key concept is that the ATP signaling and the ADO signaling systems are redundant and, hence, ensure sufficient hydration under many conditions in the normal lung.

$\mathrm{CF}$ airway epithelia are vulnerable to dehydration because of the absence of the CFTCR protein in the plasma membrane (Fig. 2B). Specifically, the adenosine$\mathrm{A}_{2 \mathrm{~b}}$ receptor system is functional, cAMP-dependent activation of PKA is functional, but the absence of CFTCR protein in the membrane renders the $\mathrm{Cl}^{-}$ secretory and $\mathrm{Na}^{+}$inhibitory effects of ADO signaling ineffective. In contrast, the ATP-P2Y-R signaling system is effective in $\mathrm{CF}$ airway epithelia in inhibiting $\mathrm{ENaC}$ and initiating $\mathrm{CaCC}$-mediated $\mathrm{Cl}^{-}$secretion. ${ }^{15}$ In vitro studies demonstrate that, under conditions that reprise tidal breathing in vivo, $\mathrm{CF}$ airway epithelia are covered by sufficient ASL to mediate normal mucociliary clearance, but they are missing a liquid reserve observed on normal airway cells. ${ }^{16}$ Importantly, the CF hydration capacity collapses if the lung is confronted with circumstances that degrade the efficacy of the ATP signaling system. A relevant in vitro observation is that infection of CF airway epithelia with paramyxoviruses, such as respiratory syncytial virus (RSV), induces CF airway epithelia to upregulate extracellular ATPase expression. ${ }^{16}$ This increased ATPase activity is sufficient to degrade the ATP in ASL and diminish/abolish P2Y $Y_{2}$ inhibition of $\mathrm{Na}^{+}$absorption and stimulation of 
A
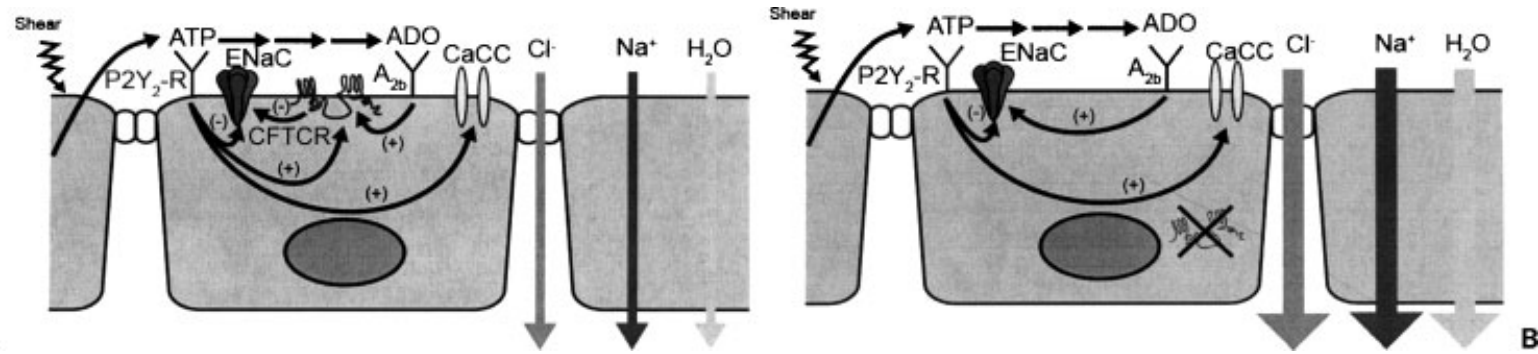

Figure 2 Constitutive and shear-dependent release of adenine triphosphate (ATP) into airway surface liquid (ASL), coupled with metabolic enzymes, produces levels of ATP and its metabolic product adenosine (ADO) that regulate the ion transport paths which control the mass of salt and ultimately water on airway surfaces. (A) In normal airways, ATP signaling through $P 2 Y_{2}$ receptors and ADO signaling through $A_{2 b}$ receptors provide redundant inhibition via the epithelial sodium channel (ENaC) (directly via $P 2 Y_{2}-R$ and indirectly via $\mathrm{A}_{2 b}$-CFTCR mechanisms) and regulation of both CFTCR- and CaCC-mediated $\mathrm{Cl}^{-}$secretion. The typical net result is a modest rate of $\mathrm{NaCl}$ and water absorption to remove ASL continually transported proximally from distal pulmonary regions. (B) In cystic fibrosis, the absence of CFTCR function at the apical membrane removes the ADO contribution to inhibition of ENaC and the CFTCR contribution to $\mathrm{Cl}^{-}$secretion. Indeed, the ADO-A ${ }_{2 b}$ regulation is redirected toward activation of ENaC. The ATP-P2Y ${ }_{2}-\mathrm{R}$ system remains intact and is the sole system to inhibit ENaC and regulate $\mathrm{CaCC}$-mediated $\mathrm{Cl}^{-}$secretion. The net effect is a tendency for increased and inappropriate $\mathrm{NaCl}$ and water absorption. This residual form of regulation is vulnerable to any exogenous insults that perturb ASL ATP concentration.

$\mathrm{CaCC}$-mediated $\mathrm{Cl}^{-}$secretion. Under these conditions, unregulated salt and liquid absorption occurs, the $\mathrm{CF}$ airway surface becomes dehydrated, mucus transport is abolished, and mucus stasis ensues. It has been speculated that a similar event may occur in CF patients in vivo during viral infections, leading to sludging of dehydrated mucus in virus-infected areas of the lung and spread of bacterial infection from bronchiectatic areas to produce an acute exacerbation. ${ }^{18,19}$

The concept that airway surface dehydration can produce CF-like lung disease was tested in an in vivo model to ascertain whether the in vitro observations cited here were pertinent to lung defense in vivo. As a test of this hypothesis, subunits of the epithelial $\mathrm{Na}^{+}$ channel were transgenically overexpressed in mice under the control of an airway-specific promoter in an attempt to tip the balance toward $\mathrm{Na}^{+}$absorption over $\mathrm{Cl}^{-}$ secretion. ${ }^{20}$ Analysis of the ion transport characteristics of mice overexpressing the $\beta \mathrm{ENaC}$ subunit revealed that $\mathrm{Na}^{+}$absorption was increased threefold over controls, whereas the ability to generate $\mathrm{Cl}^{-}$secretion in response to nucleotide-activated $\mathrm{CaCC}$ activity was not perturbed. The disturbance of the balance between absorption and secretion produced the predicted depletion of ASL volume, which resulted in mucus stasis, and death due to mucus obstruction in $\sim 50 \%$ of transgenic animals. Unexpected but important findings were that the reduction in ASL volume also produced neutrophilic inflammation and goblet cell hyperplasia that are typical features of CF lung disease. Thus, these observations provided strong evidence that a disturbance of the balance between $\mathrm{Na}^{+}$absorption and $\mathrm{Cl}^{-}$secretion, in this case by transgenically raising $\mathrm{Na}^{+}$transport rates without disturbing $\mathrm{Cl}^{-}$secretion, could produce airway surface dehydration and a phenotype quite typical of CF-like lung disease.

Finally, data from human clinical studies are consistent with the notion that dehydration is a central feature of CF lung disease. ${ }^{21-23}$ Clinical studies have also employed inhaled hypertonic saline (HS), which osmotically draws water from epithelial cells/interstitium into the airway lumen, to test whether this action restores mucus clearance and improves pulmonary function. Initial studies conducted approximately a decade ago suggested that short-term ( $\sim 2$ week) administration of $\mathrm{HS}$ to CF patients was associated with an improvement in lung function. ${ }^{24,25}$ More recently, a pair of papers revealed that the inhalation of HS (7\%, delivered by a jet nebulizer) by $\mathrm{CF}$ patients over a 2 -week period could increase the rates of mucociliary clearance and improve pulmonary function tests, and, over a 1-year interval, reduce exacerbations and improve quality of life. ${ }^{26,27}$ Importantly, the inhalation of HS for 1 year was not associated with any untoward events (e.g., increased airways inflammation or increased bacterial densities). ${ }^{27}$ These studies have spurred intense interest in the possibility that HS and other "hydration therapies" may provide a new form of therapy that treats CF lung disease at its basic cause.

\section{RATIONAL USE OF HYPERTONIC SALINE}

There are many interesting and important concepts that underlie the use of HS in CF subjects. The first is to understand reasons why $\mathrm{HS}$ is more effective in $\mathrm{CF}$ patients than in normal subjects. Second, it is important to understand that HS probes the passive permeability properties of the epithelium, and its actions should not be confused with the functions of the epithelium under physiological active ion transport modes. Some of these important concepts can be evaluated in the context of Fig. 3.

Beginning with normal airway epithelia, under baseline conditions, when ASL $\mathrm{Na}^{+}$and $\mathrm{Cl}^{-}$concentrations are isotonic, $\mathrm{Na}^{+}$is absorbed through $\mathrm{ENaC}$ in response to the apical membrane-cellular electrochemical 

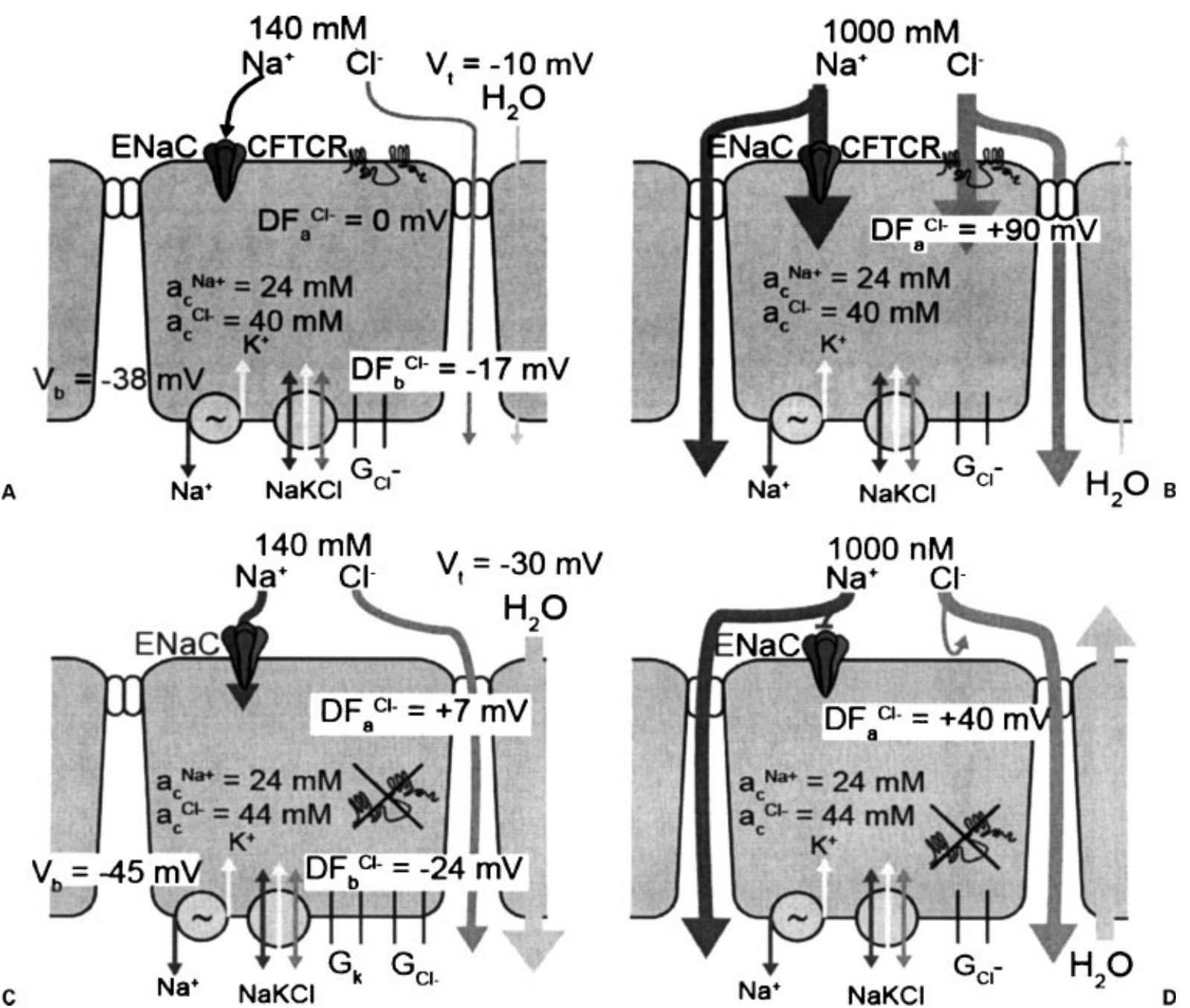

Figure 3 Ion and water transport under basal active ion transport conditions and after aerosol deposition of $7 \% \mathrm{NaCl}$ on airway surfaces. (A) Normal active ion transport: The net rate of active ion transport is determined by the rate of active $\mathrm{Na}^{+}$transport, which is a product of the electrochemical gradient favoring $\mathrm{Na}^{+}$entry across the apical membrane $\left(\mathrm{DF}_{\mathrm{a}}{ }^{\mathrm{Na}}=+60 \mathrm{mV}\right)$ and $\mathrm{Na}^{+}$extrusion across the basolateral membrane by the $\mathrm{Na}^{+} \mathrm{K}^{+}$ATPase pump. Because there is no net driving force for $\mathrm{Cl}^{-}$flow through the apical membrane CFTCR, $\mathrm{Cl}^{-}$is absorbed paracellularly in response to the transepithelial electric potential difference $\left(\mathrm{V}_{\mathrm{t}}\right)$ to preserve electroneutrality. Water accompanies $\mathrm{NaCl}$ transport through cellular and paracellular paths. Note, $\mathrm{ASL}$ is isotonic; that is, $[\mathrm{NaCl}]=\sim 140 \mathrm{mM}{ }^{39,40}(\mathrm{~B})$ Normal airways after hypertonic saline (HS) deposition. Airway surface liquid (ASL) NaCl concentrations are acutely raised ( 1000 mM at $7 \% \mathrm{NaCl}$ ). The increased concentrations of $\mathrm{Na}^{+}$and $\mathrm{Cl}^{-}$increase the chemical driving force component for $\mathrm{Na}^{+}$entry into the cell and generate a large gradient favoring cellular $\mathrm{Cl}^{-}$entry (i.e., absorption). The $\mathrm{Na}^{+}$and $\mathrm{Cl}^{-}$entering the cell exit the basolateral membrane via the pump $\left(\mathrm{Na}^{+}\right)$, cotransporters $\left(\mathrm{Na}^{+}\right.$and $\left.\mathrm{Cl}^{-}\right)$, and a basolateral $\mathrm{Cl}^{-}$channel. In parallel, there is a relatively smaller increase in Na ${ }^{+}$and $\mathrm{Cl}^{-}$absorption through the paracellular path, which is nonselective for ions, in response to the chemical gradients generated by HS deposition. Water moves in the opposite direction in response to the transient $\mathrm{NaCl}$ osmotic gradient generated by $\mathrm{HS}$ deposition. (C) Cystic fibrosis (CF) airway epithelial, active ion transport. The absence of CFTCR in the apical membrane removes a major inhibitor of the epithelial sodium channel (ENaC), producing higher basal rates of $\mathrm{Na}^{+}$transport and limiting the ability to regulate ENaC at low $\mathrm{ASL}$ volumes. The high rate of $\mathrm{Na}^{+}$transport generates a raised transepithelial potential difference (PD) $\left(V_{t}\right)$, which provides the driving force for $\mathrm{Cl}^{-}$absorption via the paracellular path to match $\mathrm{Na}^{+}$absorption. The raised net rate of $\mathrm{NaCl}$ absorption produces raised $\mathrm{H}_{2} \mathrm{O}$ absorption and a tendency for ASL volume depletion (i.e., dehydration). (D) CF airway epithelia, post-HS deposition. Again, the concentration of $\mathrm{NaCl}$ is raised in CF ASL by this maneuver to $1000 \mathrm{mM}$. Despite a large chemical driving force favoring $\mathrm{Cl}^{-}$entry into the cell from ASL, the absence of CFTCR in the membrane prevents entry of $\mathrm{Cl}^{-}$into the cell. Despite the presence of a functioning $\mathrm{ENaC}$, transcellular $\mathrm{Na}^{+}$absorption is limited by the block of cellular $\mathrm{Cl}^{-}$entry. Therefore, virtually all the $\mathrm{NaCl}$ absorption occurs via the paracellular path. Because $\mathrm{NaCl}$ absorption following $\mathrm{HS}$ deposition is limited to the paracellular path, it is slower, allowing more time for water to flow into the lumen in response to the persistent $\mathrm{NaCl}$ osmotic gradient. Thus, the ASL volume response to a given quantity of HS deposition is greater in CF than in normal airways.

gradient favoring $\mathrm{Na}^{+}$entry ${ }^{28,29}$ (Fig. 3A). Despite the fact that there is a partially active $\mathrm{CFTCR} \mathrm{Cl}^{-}$channel in the apical membrane of the normal airway epithelium, $\mathrm{Cl}^{-}$is not absorbed with $\mathrm{Na}^{+}$transcellularly, because there is no electrochemical driving force for $\mathrm{Cl}^{-}$movement across the cell membrane. ${ }^{30-32}$ Thus, $\mathrm{Cl}^{-}$is absorbed with $\mathrm{Na}^{+}$via the paracellular path, in response to the transepithelial electric potential difference (lumen 
negative) generated by active $\mathrm{Na}^{+}$transport. Isotope flux and ion-selective electrode data suggest that the overall ion conductance of the cellular path is approximately twofold greater than through the paracellular path in normal airway epithelia. ${ }^{33,34}$ Recent data suggest that water is absorbed with the actively transported $\mathrm{Na}^{+}$and $\mathrm{Cl}^{-}$ions via cellular aquaporin water channels.

For illustrative purposes, we will assume that the entire quantity of $7 \% \mathrm{HS}$ is deposited undiluted on the airway surface (note, the argument will hold with any exogenously increased $\mathrm{Na}^{+}$or $\mathrm{Cl}^{-}$concentration in ASL). It is important to note that the addition of $\mathrm{NaCl}$ to airway surfaces via inhalation of hypertonic $\mathrm{NaCl}$ is an artificial, unphysiological situation that produces an exogenously induced $\mathrm{Na}^{+}$and $\mathrm{Cl}^{-}$chemical gradient across the epithelium. In the normal airway epithelium, the increase in $\mathrm{Na}^{+}$concentration increases the electrochemical driving force for $\mathrm{Na}^{+}$to enter the cell and generates the electrochemical driving force for $\mathrm{Na}^{+}$to move through the paracellular path (Fig. 3B). Importantly, the increase in the $\mathrm{Cl}^{-}$concentration in ASL now generates an electrochemical driving force for $\mathrm{Cl}^{-}$to enter the cell via an active CFTCR and/or CaCC $\mathrm{Cl}^{-}$channel, with the residual $\mathrm{Cl}^{-}$moving through the paracellular path. The $\mathrm{Na}^{+}$and $\mathrm{Cl}^{-}$that enters the cell in response to the aerosolized HS-induced $\mathrm{NaCl}$ concentration gradient on the airway surface exits the cell through the basolateral $\mathrm{Na}^{+}-\mathrm{K}^{+}$-ATPase, a basolateral $\mathrm{Cl}^{-}$channel, and likely through the $\mathrm{Na}^{+}-\mathrm{K}^{+}-2 \mathrm{Cl}^{-}$ cotransporter. Based on the estimates of the relative permeabilities of the cell and paracellular paths for $\mathrm{Na}^{+}$and $\mathrm{Cl}^{-}$, it is estimated that approximately two thirds of the $\mathrm{NaCl}$ may move through the transcellular path in response to these imposed chemical gradients. ${ }^{33,34}$ Note that the aerosol-induced increase in $\mathrm{NaCl}$ concentration on airway surfaces produces a gradient for water to move through water channels in the opposite direction to that generated by active ion transport (i.e., there is osmotically induced water flow from the submucosa to the airway surface). Because $\mathrm{NaCl}$ is absorbed rapidly through the normal cell as well as the paracellular path after the imposition of the salt gradient, the osmotic gradient generated by $\mathrm{NaCl}$ on normal airway surfaces dissipates relatively rapidly, and only a modest amount of water moves to airway surfaces in response to this challenge (see Fig. 3B).

For CF airway epithelia, under baseline active ion transport conditions, the rate of $\mathrm{Na}^{+}$absorption is often accelerated due to the absence of CFTCR-mediated inhibition of $\mathrm{ENaC}$ (Fig. 3C). Interestingly, the absence of the CFTCR $\mathrm{Cl}^{-}$conductance per se and the absence of CFTCR inhibition of ENaC actually produces an electrochemical driving force for $\mathrm{Cl}^{-}$to be absorbed across the apical membrane of $\mathrm{CF}$ airway epithelia. ${ }^{31,32} \mathrm{How}^{-}$ ever, because of the absence of the CFTCR $\mathrm{Cl}^{-}$channel in this barrier, $\mathrm{Cl}^{-}$must move through the paracellular path to accompany the transcellular absorption of the $\mathrm{Na}^{+}$cation. The driving force that serves to match the rate of transepithelial $\mathrm{Cl}^{-}$absorption with $\mathrm{Na}^{+}$absorption is the relatively high transepithelial potential difference $(-30 \mathrm{mV}$, lumen negative) generated by a high rate of transcellular $\mathrm{Na}^{+}$absorption. The increase of $\mathrm{Na}^{+}$and $\mathrm{Cl}^{-}$transport in $\mathrm{CF}$ airway epithelia compared with normal airway epithelia produces an increase in osmotically entrained water absorption from the airway lumen to the submucosa via airway epithelial water channels.

In the case where an aerosol of 7\% HS has been used to increase the $\mathrm{NaCl}$ concentration on $\mathrm{CF}$ airway surfaces, the differences in the passive ion permeabilities of the CF airway epithelium versus normal airway epithelium are revealed. As for normal airway epithelia, when a high $\mathrm{NaCl}$ concentration in the ASL is generated by aerosol deposition of $\mathrm{HS}$ on ASL, an increase in the electrochemical gradient for $\mathrm{Na}^{+}$entry into the cell is developed (Fig. 3D). Despite the fact that an increased electrochemical gradient for cellular $\mathrm{Cl}^{-}$entry is also generated, $\mathrm{Cl}^{-}$cannot enter the cell due to the absence of the CFTCR $\mathrm{Cl}^{-}$channel in the apical membrane. The only available path for cellular $\mathrm{Cl}^{-}$to be absorbed across the $\mathrm{CF}$ airway epithelium, in response to the chemical gradients generated by the deposition of $\mathrm{NaCl}$ via aerosols in ASL, is the paracellular path.

Data from radioisotopic and electrophysiological techniques suggest that the paracellular path permeability to $\mathrm{NaCl}$ is not different in $\mathrm{CF}$ versus normal airway epithelial cells. ${ }^{7,30-32,35}$ Therefore, because CF airway epithelia can absorb the aerosol-deposited $\mathrm{NaCl}$ only via the paracellular path, the rate of absorption/dissipation of the salt gradient will be reduced by $\sim 60$ to $70 \%$ as compared with normal airway epithelia, reflecting the absence of a cellular route for $\mathrm{Cl}^{-}$absorption in $\mathrm{CF}$ airway epithelia. The slower rate of $\mathrm{NaCl}$ absorption leads to a relative retention of $\mathrm{NaCl}$ on $\mathrm{CF}$ airway surfaces. Thus the osmotic gradient favoring water flow generated by the aerosolized $\mathrm{NaCl}$ persists for longer periods of time in $\mathrm{CF}$ than normal airway epithelia, leading to increased volumes of water on $\mathrm{CF}$ versus normal epithelial surfaces (see Fig. 3D). Interestingly, this inability to absorb $\mathrm{Cl}^{-}$passively via an artificially imposed $\mathrm{Cl}^{-}$gradient, producing increases in ASL volume, may be the only "break" CF patients get with respect to therapy of their lung disease.

Note, at the large $\mathrm{NaCl}$ concentration gradients (10s to $100 \mathrm{~s} \mathrm{mM}$ ) generated by HS deposition on CF airway surfaces, the $\mathrm{Cl}^{-}$conductance of the paracellular path is limiting for $\mathrm{Na}^{+}$and, hence, net $\mathrm{NaCl}$ absorption. Under baseline conditions where $\mathrm{CF}$ active ion transport determines ASL volume, active $\mathrm{Na}^{+}$transport generates $\mu \mathrm{M}$ salt gradients across $\mathrm{CF}$ airway epithelia. At physiologic transport rates, the $\mathrm{Cl}^{-}$conductance of the paracellular path is not limiting, so the rate of active $\mathrm{Na}^{+}$ transport determines ASL volume. These considerations 
resolve the apparent paradox of the importance of the absent cellular CFTCR $\mathrm{Cl}^{-}$conductance in the response of the $\mathrm{CF}$ airway to aerosolized $\mathrm{HS}$ versus the relative unimportance of the cellular $\mathrm{Cl}^{-}$conductance in the abnormal $\mathrm{NaCl}$ absorptive states that are a feature of $\mathrm{CF}$ airways under basal conditions.

\section{THE EFFECT OF AMILORIDE PRETREATMENT ON HYPERTONIC SALINE EFFICACY}

An observation that led to some confusion and controversy pertaining to the paper of Donaldson et $\mathrm{al}^{26}$ was the fact that amiloride blunted the responses of $\mathrm{CF}$ airway epithelia to $\mathrm{HS}^{36}$ (see Fig. 4A). It had been predicted that by blocking the cellular path for $\mathrm{Na}^{+}$ absorption, the amiloride-induced block of $\mathrm{ENaC}$ would slow the active epithelial absorption of $\mathrm{Na}^{+}$(and $\mathrm{Cl}^{-}$) across the epithelium. This effect was predicted to promote a longer duration of the aerosolized HS deposited on airway surfaces that would subsequently be rendered isotonic via the osmotically driven movement of water. ${ }^{37}$ Surprisingly, what was observed was that administration of amiloride blocked the initial volume response so that it was not possible to ascertain whether amiloride slowed the subsequent active absorption of ASL (Fig. 4A). Because it seemed implausible that amiloride would accelerate the absorption of $\mathrm{Na}^{+}$and $\mathrm{Cl}^{-}$across the $\mathrm{CF}$ airways epithelium, studies were initiated to ascertain whether amiloride had a second action on airway epithelial salt and water transport (e.g., blocked epithelial water permeability). These studies

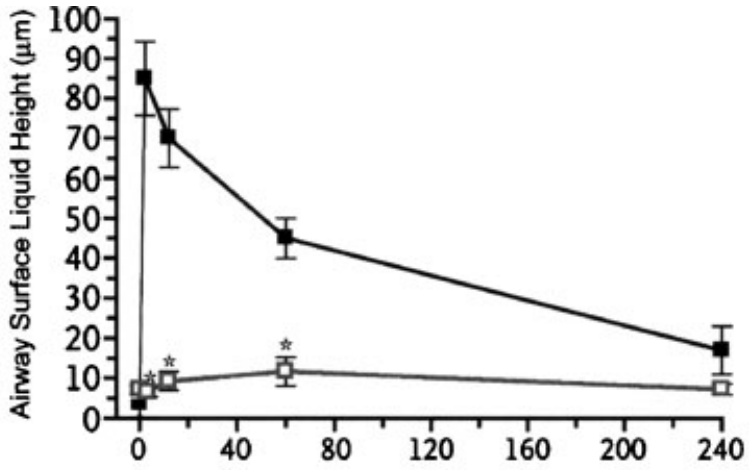

A Minutes

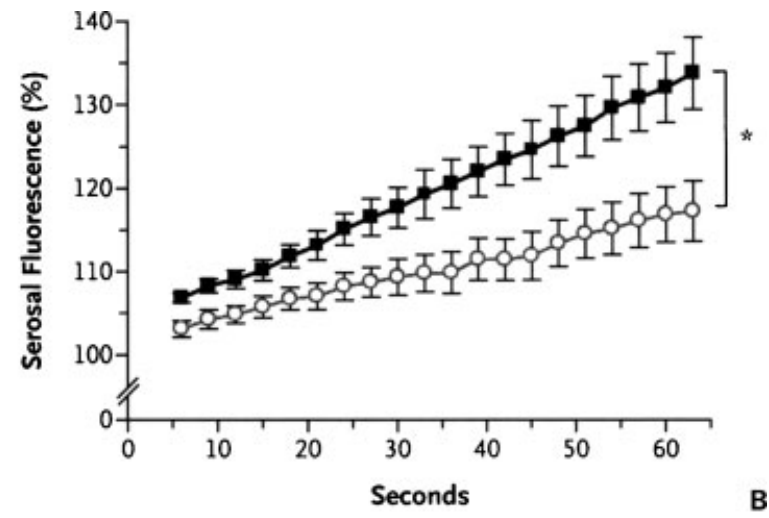

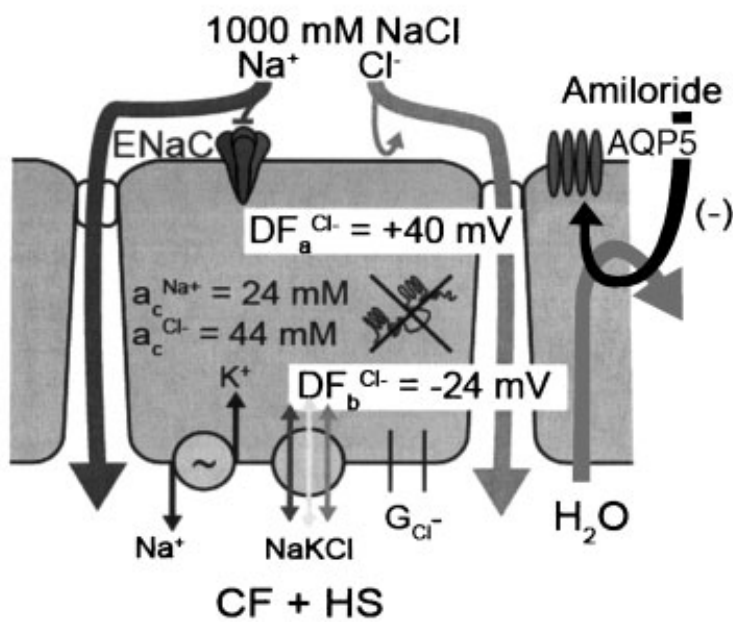

Figure 4 Effect of amiloride on hypertonic saline (HS)-induced airway surface liquid (ASL) volume responses. (A) Confocal measurements of ASL height/volume in cystic fibrosis (CF) airway epithelia in response to $7 \%$ HS without (घ) and with ( $\square$ ) amiloride $\left(3 \times 10^{-4} \mathrm{M}\right)$ pretreatment. ${ }^{*}$ Different from HS alone $(p<.05)$. (B) Effect of amiloride on osmotically induced water flow across CF airway epithelia. Cultured CF airway epithelia were placed on a confocal microscope with a fluorescent, impermeant probe in the basolateral bath. At $t=0$, hypertonic mannitol was placed in the luminal bath and the flow of water from the basolateral to the luminal bath measured from the increase in serosal bath fluorescence (i.e., concentration of the serosal bath probe increased as water moved into the luminal compartment). This assay was performed without $(\mathbf{\square})$ and with $(\bigcirc)$ amiloride $\left(3 \times 10^{-4} \mathrm{M}\right)$ administration to the lumen 10 minute prior to osmotic challenge. * Different from without amiloride pretreatment $(p<0.05)$. (C) Speculated cellular action of amiloride on transepithelial water flow after HS administration. The deposited HS produces the increase in ASL [NaCl], as depicted in Fig. 3D. Again, the absence of a path for $\mathrm{Cl}^{-}$absorption limits $\mathrm{NaCl}$ absorption to the paracellular path. It is speculated that amiloride slows water flow in response to the $\mathrm{HS}$-generated $\mathrm{NaCl}$ gradient by inhibiting aquaporin 5 in the apical membrane. This action allows $\mathrm{NaCl}$ absorption to occur relatively more rapidly than water flow into the lumen, greatly decreasing the ASL volume expansion in response to HS administration. 
revealed that amiloride at high concentrations blocked transepithelial water flows in response to osmotic gradients generated by added $\mathrm{NaCl}$ or a nonionic solute, mannitol (Fig. 4B). Although the precise mechanisms are not known, it appears from subsequent studies that amiloride may block the aquaporin 5 channel that is an important water channel in the apical membrane of normal and $\mathrm{CF}$ airway epithelia. Thus, as shown in Fig. $4 \mathrm{C}$, a partial block of the apical membrane water channel slows water movement toward the lumen in response to the aerosol-imposed $\mathrm{NaCl}$ gradient, allowing the $\mathrm{NaCl}$ gradient to be dissipated through the paracellular path. Thus the "kinetic horse race" between the absorption of $\mathrm{NaCl}$ via the paracellular path versus the movement of water toward the lumen via the cellular path is tipped in favor of paracellular $\mathrm{NaCl}$ absorption via the actions of amiloride. The net effect is a reduced volume response to the aerosol-generated salt gradient.

Interestingly, amiloride might have been therapeutically useful if given after HS rather than as a pretreatment. That is, amiloride would have blocked the active absorption of $\mathrm{Na}^{+}$(and $\mathrm{Cl}^{-}$). Because, as noted earlier, the gradients of $\mathrm{NaCl}$ across the epithelium generated by active $\mathrm{Na}^{+}$(and $\mathrm{Cl}^{-}$) absorption are very low $(\mu \mathrm{M})$ as compared with aerosol deposition of salt $(\mathrm{mM})$, any amiloride block of water flow would have negligible effects on osmotic water flow coupled to active ion transport. However, the clinical utility of delivering amiloride after HS may be minimal because the half-life of amiloride on airway surfaces is short ( 30 min).

\section{THE FUTURE OF HYDRATION THERAPIES}

A central question will be the position of $\mathrm{HS}$ within the spectrum of therapies available to $\mathrm{CF}$ patients. On one level, because HS may treat the initiating cause of CF lung disease, it may make sense to make HS the "base" therapy for CF patients. However, the current experience principally reflects administration of HS with pressure-driven nebulizers to adolescents and young adults. Studies are under way to transition the delivery of HS to more time-efficient devices (e.g., ultrasonic devices) that can also be more easily interfaced to infants. Thus important studies that will soon be initiated are ones designed to test whether inhaled HS in infants over a 1-year period can forestall the decrements in lung function and the abnormalities in CT (air trapping/ bronchiectasis) that characterize this period. Similar studies are under way in 4- to 6-year-old cohorts to ascertain whether HS can arrest the decrement of lung function typically seen in this age group.

Because the initiating events of many acute exacerbations in $\mathrm{CF}$ are viral infections that may induce mucus sludging in airways that were previously "quasinormally" hydrated via the actions of ATP (see earlier), it may make sense to study relationships between HS therapy and exacerbations. Because this thesis has not been tested, it will be important to generate randomized trials to ascertain whether maximization of HS therapy at the time the CF patient clinically senses a "virus" will forestall an exacerbation. In parallel, studies may also be warranted to test whether maximization of HS-mediated hydration will shorten the interval of the exacerbation and improve the outcome of therapy for exacerbations.

Finally, HS does have limitations with respect to the therapy of $\mathrm{CF}$ lung disease. For example, $\mathrm{HS}$ at $7 \%$ can be irritating to some patients and cause bronchoconstriction. Similarly, particularly in children, the taste of HS is a detriment to chronic use of this agent. Perhaps most importantly, it is difficult to deliver HS efficiently to the very large surface area of the small airways/ bronchioles that appear to be the site of initiation of CF lung disease. ${ }^{38-40}$ This phenomenon reflects the simple aerosol physics parameters of the modern nebulizer, which deposits approximately equal volumes of aerosol on the relatively small surface area of central airways compared with the relatively large surface area of small airways. Because the hydration effect of HS is a linear function of the amount of salt deposited on airway surfaces, the small airways will always be less well treated by HS. Thus, it may be advantageous in the future to utilize approaches that hydrate airway surfaces by inducing secretion of $\mathrm{NaCl}$ via receptor-mediated pathways that can be fully activated by potent ligands delivered to small airway surfaces, for example, stabilized nucleotide molecules (INS37217), or by the coadministration of new, potent, long-acting $\mathrm{Na}^{+}$channel blockers that will retain all $\mathrm{NaCl}$ added to small airway surfaces to amplify the hydrating effects of HS in this region. It is likely that the requirement to effectively treat the bronchiole will be a central feature of any hydrating regimen to, in a most assured fashion, prevent and/or arrest the progression of lung disease in CF patients.

\section{REFERENCES}

1. Davis PB. Cystic fibrosis since 1938. Am J Respir Crit Care Med 2006;173:475-482

2. Kerem B, Rommens JM, Buchanan JA, et al. Identification of the cystic fibrosis gene: genetic analysis. Science 1989;245: 1073-1080

3. Riordan JR, Rommens JM, Kerem B-T, et al. Identification of the cystic fibrosis gene: cloning and characterization of complementary DNA. Science 1989;245:1066-1073

4. Guggino WB, Stanton BA. New insights into cystic fibrosis: molecular switches that regulate CFTCR. Nat Rev Mol Cell Biol 2006;7:426-436

5. Anderson MP, Rich DP, Gregory RJ, Smith AE, Welsh MJ. Generation of cAMP-activated chloride currents by expression of CFTCR. Science 1991;251:679-682

6. Jia Y, Mathews CJ, Hanrahan JW. Phosphorylation by protein kinase $\mathrm{C}$ is required for acute activation of cystic 
fibrosis transmembrane conductance regulator by protein kinase A. J Biol Chem 1997;272:4978-4984

7. Boucher RC, Stutts MJ, Knowles MR, Cantley L, Gatzy JT. $\mathrm{Na}^{+}$transport in cystic fibrosis respiratory epithelia: abnormal basal rate and response to adenylate cyclase activation. J Clin Invest 1986;78:1245-1252

8. Stutts MJ, Canessa CM, Olsen JC, et al. CFTCR as a cAMP-dependent regulator of sodium channels. Science 1995;269:847-850

9. Cheng SH, Gregory RJ, Marshall J, et al. Defective intracellular transport and processing of CFTCR is the molecular basis of most cystic fibrosis. Cell 1990;63:827-834

10. Riordan JR. Assembly of functional CFTCR chloride channels. Annu Rev Physiol 2005;67:701-718

11. Matsui H, Grubb BR, Tarran R, et al. Evidence for periciliary liquid layer depletion, not abnormal ion composition, in the pathogenesis of cystic fibrosis airways disease. Cell 1998;95:1005-1015

12. Matsui H, Randell SH, Peretti SW, Davis CW, Boucher RC. Coordinated clearance of periciliary liquid and mucus from airway surfaces. J Clin Invest 1998;102:1125-1131

13. Matsui H, Davis CW, Tarran R, Boucher RC. Osmotic water permeabilities of cultured, well-differentiated normal and cystic fibrosis airway epithelia. J Clin Invest 2000;105: 1419-1427

14. Tarran R, Trout L, Donaldson SH, Boucher RC. Soluble mediators, not cilia, determine airway surface liquid volume in normal and cystic fibrosis superficial airway epithelia. J Gen Physiol 2006;127:591-604

15. Mall $\mathrm{M}$, Wissner $\mathrm{A}$, Gonska $\mathrm{T}$, et al. Inhibition of amiloride-sensitive epithelial $\mathrm{Na}(+)$ absorption by extracellular nucleotides in human normal and cystic fibrosis airways. Am J Respir Cell Mol Biol 2000;23:755-761

16. Tarran R, Button B, Picher M, et al. Normal and cystic fibrosis airway surface liquid homeostasis: the effects of phasic shear stress and viral infections. J Biol Chem 2005; 280:35751-35759

17. Tarran R, Button B, Boucher RC. Regulation of normal and cystic fibrosis airway surface liquid volume by phasic shear stress. Annu Rev Physiol 2006;68:543-561

18. van Ewijk BE, van der Zalm MM, Wolfs TF, van der Ent CK. Viral respiratory infections in cystic fibrosis. J Cyst Fibros 2005;4(Suppl 2):31-36

19. Abman SH, Ogle JW, Butler-Simon N, Rumack CM, Accurso FJ. Role of respiratory syncytial virus in early hospitalizations for respiratory distress of young infants with cystic fibrosis. J Pediatr 1988;113:826-830

20. Mall M, Grubb BR, Harkema JR, O’Neal WK, Boucher RC. Increased airway epithelial $\mathrm{Na}^{+}$absorption produces cystic fibrosis-like lung disease in mice. Nat Med 2004;10: 487-493

21. Matthews LW, Spector S, Lemm J, Potter JL. Studies on pulmonary secretions, I: The overall chemical composition of pulmonary secretions from patients with cystic fibrosis, bronchiectasis, and laryngectomy. Am Rev Respir Dis 1963; 88:199-204

22. Potter JL, Matthews LW, Spector S, Lemm J. Studies of pulmonary secretions, II: Osmolarity and the ionic environment of pulmonary secretions from patients with cystic fibrosis, bronchiectasis and laryngectomy. Am Rev Respir Dis 1967;96:83-87
23. Zuelzer WW, Newton WA Jr. The pathogenesis of fibrocystic disease of the pancreas: a study of 36 cases with special reference to the pulmonary lesions. Pediatrics 1949; 4:53-69

24. Eng PA, Morton J, Douglass JA, Riedler J, Wilson J, Robertson CF. Short-term efficacy of ultrasonically nebulized hypertonic saline in cystic fibrosis. Pediatr Pulmonol 1996; 21:77-83

25. Robinson M, Regnis JA, Bailey DL, King M, Bautovich GJ, Bye PT. Effect of hypertonic saline, amiloride, and cough on mucociliary clearance in patients with cystic fibrosis. Am J Respir Crit Care Med 1996;153:1503-1509

26. Donaldson SH, Bennett WD, Zeman KL, Knowles MR, Tarran R, Boucher RC. Mucus clearance and lung function in cystic fibrosis with hypertonic saline. N Engl J Med 2006; 354:241-250

27. Elkins MR, Robinson M, Rose BR, et al. A controlled trial of long-term Inhaled hypertonic saline in patients with cystic fibrosis. N Engl J Med 2006;354:229-240

28. Willumsen NJ, Boucher RC. Sodium transport and intracellular sodium activity in cultured human nasal epithelium. Am J Physiol 1991;261(2 Pt 1):C319-C331

29. Willumsen NJ, Boucher RC. Transcellular sodium transport in cultured cystic fibrosis human nasal epithelium. Am J Physiol 1991;261(2 Pt 1):C332-C341

30. Willumsen NJ, Davis CW, Boucher RC. Cellular $\mathrm{Cl}^{-}$ transport in cultured cystic fibrosis airway epithelium. Am J Physiol 1989;256(5 Pt 1):C1045-C1053

31. Willumsen NJ, Davis CW, Boucher RC. Intracellular $\mathrm{Cl}^{-}$ activity and cellular $\mathrm{Cl}^{-}$pathways in cultured human airway epithelium. Am J Physiol 1989;256(5 Pt 1):C1033-C1044

32. Willumsen NJ, Boucher RC. Shunt resistance and ion permeabilities in normal and cystic fibrosis airway epithelium. Am J Physiol 1989;256(5 Pt 1):C1054-C1063

33. Knowles MR, Stutts MJ, Spock A, Fischer N, Gatzy JT, Boucher RC. Abnormal ion permeation through cystic fibrosis respiratory epithelium. Science 1983;221:1067-1070

34. Knowles M, Murray G, Shallal J, et al. Bioelectric properties and ion flow across excised human bronchi. J Appl Physiol 1984;56:868-877

35. Willumsen NJ, Boucher RC. Activation of an apical $\mathrm{Cl}^{-}$ conductance by $\mathrm{Ca}^{2+}$ ionophores in cystic fibrosis airway epithelia. Am J Physiol 1989;256(2 Pt 1):C226-C233

36. Levin MH, Sullivan S, Nielson D, Yang B, Finkbeiner WE, Verkman AS. Hypertonic saline therapy in cystic fibrosis: evidence against the proposed mechanism involving aquaporins. J Biol Chem 2006;281:25803-25812

37. Tarran R, Grubb BR, Parsons D, et al. The CF salt controversy: in vivo observations and therapeutic approaches. Mol Cell 2001;8:149-158

38. Sood N, Bennett WD, Zeman K, et al. Increasing concentration of inhaled saline with or without amiloride: effect on mucociliary clearance in normal subjects. Am J Respir Crit Care Med 2002;167:158-163

39. Knowles MR, Robinson JM, Wood RE, et al. Ion composition of airway surface liquid of patients with cystic fibrosis as compared to normal and disease-control subjects. J Clin Invest 1997;100:2588-2595

40. Kotaru C, Hejal RB, Finigan JH, et al. Desiccation and hypertonicity of the airway surface fluid and thermally induced asthma. J Appl Physiol 2003;94:227-233 